\title{
Germinal mosaicism increases the recurrence risk for 'new' Duchenne muscular dystrophy mutations
}

\author{
E BAKKER*, H VEENEMA*, J T DEN DUNNEN*, \\ C VAN BROECKHOVEN $\dagger$, P M GROOTSCHOLTEN*, E J BONTEN*, \\ G J B VAN OMMEN*, AND P L PEARSON* \\ From * the Department of Human Genetics, Sylvius Laboratories, Wassenaarseweg 72, 2333AL Leiden, The \\ Netherlands; and the Department of Biochemistry, University of Antwerp, Belgium.
}

SUmmaRY In 288 Dutch and Belgian Duchenne and Becker muscular dystrophy families, the parental origin of 41 new deletion or duplication mutations was determined. Twenty seven of the new mutations occurred in the maternal X chromosome and nine in the grandmaternal and five in the grandpaternal $\mathrm{X}$ chromosome. The grandparental data are compatible with equal mutation rates for DMD in male and female $X$ chromosomes. New mutations were defined by their presence in one or more progeny and absence in the lymphocytes of the mother or the grandparents. In one family a fraction of the maternal lymphocytes was found to carry the mutation, suggesting somatic mosaicism. In six cases out of 41 , the mutation was transmitted more than once by a parent in whom the mutation was absent in lymphocytes, suggesting gonadal mosaicism as the explanation for the multiple transmission. Using our data for the recurrence of the mutations among the total of at risk haplotypes transmitted, we arrive at a recurrence risk of $14 \%$ for the at risk haplotype. The observation of this high risk of germinal mosaicism is crucially important for all physicians counselling females in DMD families. Recently, germinal mosaicism has been observed also in a number of other $\mathrm{X}$ linked and autosomal disorders. The implications and appropriate diagnostic precautions are discussed.

Duchenne muscular dystrophy (DMD), a lethal, recessive $\mathrm{X}$ linked disorder, affects boys in early childhood and most DMD patients die before the age of 20 years. This severe disorder has a frequency of $1: 3500$ live male births. ${ }^{1}$ The a priori carrier risk for mothers of sporadic DMD patients is $66 \%$. The existence of unaffected sons and brothers, in combination with low maternal blood creatine kinase (CK) levels, reduce this risk. Recently, carrier detection and first trimester prenatal diagnosis, using a combination of flanking, intragenic, and cDNA probes, has attained over $99 \%$ reliability in up to $90 \%$ of the cases. ${ }^{2-7}$ On both Southern and FIGE blots, approximately $66 \%$ of DMD patients show deletions or duplications of part of the coding sequences. $^{8-10}$ The total DMD cDNA is $14 \mathrm{~kb}$ long, ${ }^{11}$ comprising about 76 exons spread over about 2.3 million base pairs of genomic DNA. ${ }^{12}$ One-third of DMD patients are believed to result from a 'new' mutation, ${ }^{13}$ and the DMD mutation frequency has been estimated as $0.01 \%$. In the early seventies,

Received for publication 23 February 1989

Revised version accepted for publication 12 April 1989. both $\mathrm{Hartl}^{14}$ and Murphy et al ${ }^{15}$ addressed the problem of germinal mosaicism of $X$ linked recessive disorders in genetic counselling on statistical grounds. Hartl ${ }^{14}$ postulated that the recurrence risk would be less than $5 \%$ if one son was affected and 20 to $35 \%$ if two or more sons were affected and proposed not to use these figures in routine counselling. Murphy et $\mathrm{al}^{15}$ claimed that in any family of realistic size, ignoring gonadal mosaicism would have little effect on the risk estimate for the next child.

However, since the advent of direct detection of DMD mutations, the recurrence of presumptive germinal mosaicism has been reported by a number of research groups. ${ }^{16-19}$ Germline mosaicism in both male and female 'carriers' generates a recurrence risk for transmitters and patients of 'new' DMD mutations. In this study, we compile our overall new mutation data to determine the frequency with which the new mutation is transmitted for a second time. Information on the male and female contribution to DMD deletion or duplication mutations is obtained from haplotype information. The recurrence risks for new mutations and the consequences 
TABLE $1 X p$ probes used in the diagnostic service for carrier detection and prenatal diagnosis of DMD and BMD (see also Pearson et $\mathrm{al}^{20}$ ).

\begin{tabular}{llll}
\hline $\begin{array}{l}\text { Genomic } \\
\text { probes }\end{array}$ & Locus & $\begin{array}{l}\text { cDNA } \\
\text { probes }\end{array}$ & $\begin{array}{l}\text { Location in the } \\
\text { DMD gene } \\
\left(5^{\prime}-3^{\prime} k b\right)\end{array}$ \\
\hline L1.28 & & $\begin{array}{l}1-2 \\
\text { OTC }\end{array}$ & XJ10 \\
cX5.7 & DXS7 & $9-7$ & $1-2 \mathrm{a}$ \\
754 and 754-11 & OTC & $30-2$ & $2 \mathrm{~b}-3 \mathrm{a}$ \\
XJ1.1, 1.2, 2.3 & DXS148 & $30-1$ & $3 \mathrm{~b}-5 \mathrm{a}$ \\
P87-1, 8, 15, 30, 42 & DXS84 & $47-4$ & $5 \mathrm{~b}-7$ \\
Jbir & DXS206 & $44-1$ & 8 \\
P20 & DXS270 & $63-1$ & $9-14$ \\
J66 & DXS269 & & \\
C7 & DXS268 & & \\
99.6 & $D X S 28$ & & \\
pD2 & $D X S 41$ & & \\
782 & $D X S 43$ & & \\
\hline
\end{tabular}

for genetic counselling are discussed and a strategy is presented for safeguarding against diagnostic calamities.

\section{Subjects and methods}

The family material used in this study was sent to us as blood samples, fibroblasts, and chorionic villi samples by a number of counselling units covering a referral population of 14 million in The Netherlands and 5 million in Belgium, which make use of the diagnostic laboratories in Leiden and Antwerp.

The methods for DNA analysis used have been described earlier. ${ }^{34812}$ The probes used are listed in table 1; for more detailed information about these probes see the HGM9 recombinant DNA report. ${ }^{20}$

\section{Results}

Out of a total of 288 families (246 Dutch and 42 Belgian) studied for carrier detection, 156 families were referred with isolated cases of DMD. Prenatal diagnosis was performed on 53 male fetuses in 47 Dutch families. $^{4}$

The presence of new mutations was determined using both genomic flanking and intragenic RFLP probes and cDNA probes (the latter kindly provided by Drs Kunkel and Worton). Deletion or duplication mutations were detected in 168 cases out of the $288(58 \%)$ families studied. In 42 of the 168 cases $(25 \%)$ the mutation was found to be a new one. Two of these, although they appeared as familial cases, were found to involve (recurrent) new deletion mutations. We have derived the parental origin of the mutation in 41 new mutation cases using the $X$ haplotype information (table 2). In five cases the grandpaternal haplotype underwent the mutation, while nine originated in a grandmaternal $\mathrm{X}$ chromosome. The 27 remaining mutations originated in the mother (fig 1). Fig 1 shows that in this small set of unbiased data the mutation rates for DMD in grandparental male and female $\mathrm{X}$ chromosomes are equal for each chromosome.

In six pedigrees, including the two cases originally identified as familial, the recurrence of a new mutation was observed (fig 2). In family DL202 (fig 2d) a duplication was detected with the cDNA probe cDNA1-2 or cDNA-XJ10 (HindIII bands 2, 3, 7, 8, and $12 \mathrm{a} ; E c o$ RI bands 2, 5, 6, and 10, data not shown) in the patient and both his mother and his aunt. Both grandparents lacked this duplication in their lymphocytes, but because of non-informativeness we were not able to detect the origin in this

TABLE 2 List of families with proven new mutations.

\begin{tabular}{|c|c|c|c|c|c|}
\hline \multirow{2}{*}{$\begin{array}{l}\text { Pedigree } \\
\text { No }\end{array}$} & \multirow{2}{*}{$\begin{array}{l}\text { Type of } \\
\text { mutation }\end{array}$} & \multirow{2}{*}{$\begin{array}{l}\text { Origin of } \\
\text { mutation }\end{array}$} & \multicolumn{2}{|c|}{ At risk haplotype } & \multirow{2}{*}{$\begin{array}{l}\text { Germline } \\
\text { mosaic }\end{array}$} \\
\hline & & & Affected & Normal & \\
\hline BL 1 & del P20 & $\mathbf{M}$ & 1 & 2 & \\
\hline BL 15 & del XJ1.1 & $\mathbf{M}^{*}$ & 1 & 2 & \\
\hline DL 40 & del $47-4$ & $\mathbf{M}$ & 1 & 0 & \\
\hline DL 43 & del $\mathrm{XJ} 10$ & $\mathbf{M}$ & 2 & 1 & $\mathbf{X}$ \\
\hline DL 55 & del p87-8 & $\mathbf{P}$ & 1 & 1 & \\
\hline DL 62 & del p87-42 & $\mathbf{M}^{*}$ & 1 & 2 & \\
\hline DL 68 & del $47-4$ & $\mathbf{M}$ & $i$ & 2 & \\
\hline DL 70 & del 44-1 & $\mathbf{M}$ & 1 & 0 & \\
\hline DL 86 & del p87-15 & $\mathbf{M}$ & 1 & 1 & \\
\hline DL 88 & del 44-1 & $\mathbf{M}$ & 1 & 1 & \\
\hline DL 96 & del P20 & $\mathbf{M}^{*}$ & 1 & 1 & \\
\hline DL101 & del 44-1 & $\mathbf{M}$ & 1 & 0 & \\
\hline DL104 & del 44-1 & $\mathbf{M}$ & $i$ & 0 & \\
\hline DL114 & del $30-1$ & $\mathbf{M}$ & 2 & $1+$ & $\mathbf{x}$ \\
\hline DL129 & del 44-1 & $\mathbf{M}$ & 1 & 1 & \\
\hline DL133 & del Jbir & $\mathbf{M}$ & 1 & 0 & \\
\hline DL139 & del 44-1 & $\mathbf{M}^{*}$ & 1 & 2 & \\
\hline DL140 & del $C 7$ & $\mathbf{P}$ & 1 & 0 & \\
\hline DL145 & del 63-1 & $\mathbf{M}$ & 1 & 2 & \\
\hline DL146 & del $63-1$ & $\mathbf{M}$ & $i$ & 0 & \\
\hline DL149 & del P20 & $\mathbf{M}$ & 1 & 0 & \\
\hline DL151 & del XJ10 & $\mathbf{M}$ & 1 & 0 & \\
\hline DL154 & del p87 & $\mathbf{M}^{*}$ & 2 & 0 & $\mathbf{x}$ \\
\hline DL162 & del $47-4$ & $\mathbf{M}$ & 1 & 1 & \\
\hline DL170 & del XJ10 & $\mathbf{M}$ & 1 & 1 & \\
\hline DL202 & dup $\mathrm{XJ} 10$ & $\mathbf{P}$ or $\mathbf{M}^{*}$ & 2 & $1(2)$ & $\mathbf{X}$ \\
\hline DL211 & del 63-1 & $\mathrm{P}$ & 1 & 1 & \\
\hline DL221 & del XJ10 & $\mathbf{M}$ & 1 & 1 & \\
\hline DL222 & del XJ10 & $\mathbf{M}$ & $i$ & $i$ & \\
\hline DL225 & del $44-1$ & $\mathbf{M}$ & 1 & $i$ & \\
\hline DL233 & del 44-1 & $\mathbf{M}$ & 1 & 0 & \\
\hline DL236 & del 44-1 & $\mathbf{P}$ & 1 & 0 & \\
\hline MD 3 & del p87 & $\mathbf{M}^{*}$ & 1 & 1 & \\
\hline MD 5 & del 44-1 & $\mathbf{M}$ & 1 & 3 & \\
\hline MD 6 & del p87 & $\mathbf{M}$ & 2 & 0 & $\mathbf{X}$ \\
\hline MD 7 & del 44-1 & $\mathbf{P}$ & 1 & 0 & \\
\hline MD 11 & del P20 & $\mathbf{M}^{*}$ & 1 & 3 & \\
\hline MD 14 & del p87 & $\mathbf{M}$ & 2 & 0 & $\mathbf{X}$ \\
\hline MD 18 & del $9-7$ & $\mathbf{M}$ & 1 & 1 & \\
\hline MD 20 & del $44-1$ & $\mathbf{M}^{*}$ & $i$ & 1 & \\
\hline MD 27 & del $44-1$ & $\mathbf{M}$ & 1 & 0 & \\
\hline MD 40 & del 44-1 & $\mathbf{M}^{*}$ & 1 & 0 & \\
\hline
\end{tabular}

Total 42 families (see also figs 1 and 6 ). $t=$ somatic mosaicism.

$\mathbf{M}=$ maternal origin of the mutation (27).

$\mathbf{M}^{*}=$ grandmaternal origin of the mutation (9).

$\mathbf{P}=$ grandpaternal origin of the mutation (5).

At risk haplotype transmitted 41 times, 35 not affected.

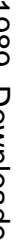






FIG 1 New mutations observed in the DMD gene. In 42 families a new DMD mutation was detected. In 27 cases the mother of the patient was not deleted. In nine cases the grandmother's X chromosome was found to have undergone the new mutation in the mother of the patient, and in five cases the grandfather's $X$ chromosome. In one case the mutation was grandparental, but haplotype information did not allow discrimination between the grandfather's and grandmother's $X$ (fig 2). twice transmitted new mutation. Southern blot data on families DL43, MD14, and DL114 are shown in figs 3 to 5. Similar data on families DL154 and MD6 have been published earlier. ${ }^{16}$ In fig $3 a$, family DL43 (see also fig 2c) hybridised with the cDNA1-2 probe shows a deletion of the $X m n I$ bands 2,6 , and 9 in the patient (lane 7).

The mother of the patient (lane 3 ) is heterozygous for the deletion while the grandmother does not carry the deletion. This is more clearly observed in a $P v u I I$ digest (fig 3b) where the patient (lane 7) is missing bands 1 and 5 and has gained a junction band. This band is also present in the carrier mother, but not in lymphocytes of the grandmother, who has transmitted the DMD mutation twice. Fig 4a shows a TaqI digest of family MD14 (see fig 2d). The DNA of the patient (lane 4) shows a deletion for XJ1.1 (DXS206). The mother (lane 2) shows two alleles of XJ1.1 while her daughter, who carries the deletion, has only one copy of the $\mathrm{XJ} 1.1$ allele.

In fig $5 \mathrm{~d}$ the blot of family DL114 is shown, in which the mutation causes a junction band. In this case the mother carries the mutation (lane 1), but probably not in all her cells, because she transmitted
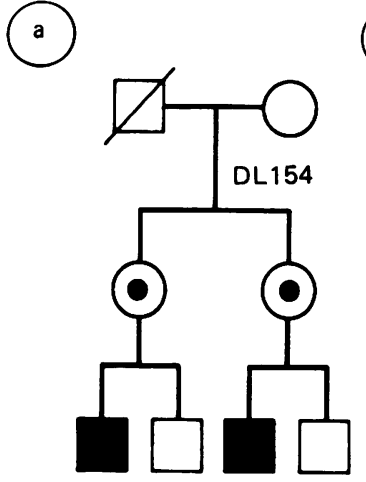

(d)

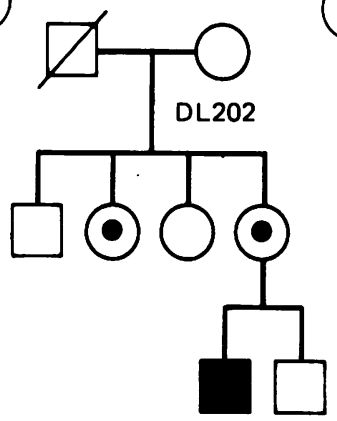

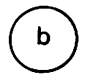
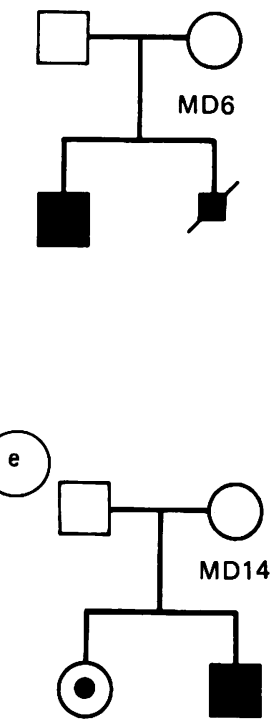
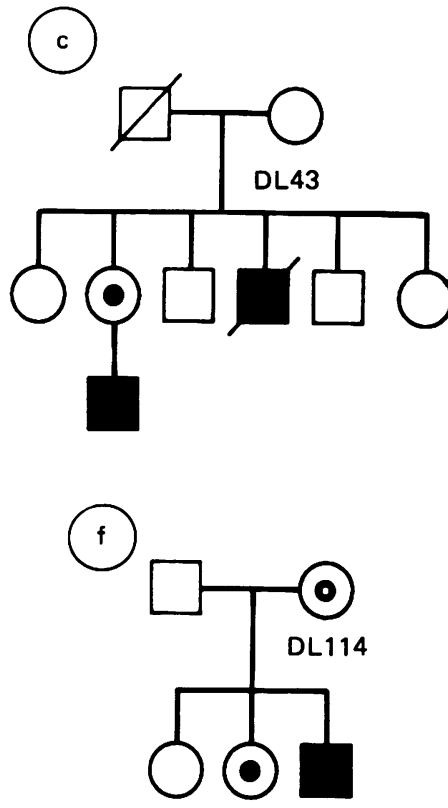

FIG 2 Six pedigrees $(a-f)$ in which a germinal mosaic situation was observed (see also table 1). In five cases the mutation was a partial deletion of the DMD gene, while in family DL202 (d) a duplication of exonic sequences was observed. Because oflack of haplotype information we werenot able to determine if the duplication had occurred in the paternal or maternal $X$ chromosome. The grandmother was not carrying the mutation (data not shown) and the grandfather was not a DMD patient; therefore this is clearly a recurrent new mutation. In family DL114 (f) the mutation was also present as a somatic mosaic mutation in the mother of the patient (see also fig 5). 


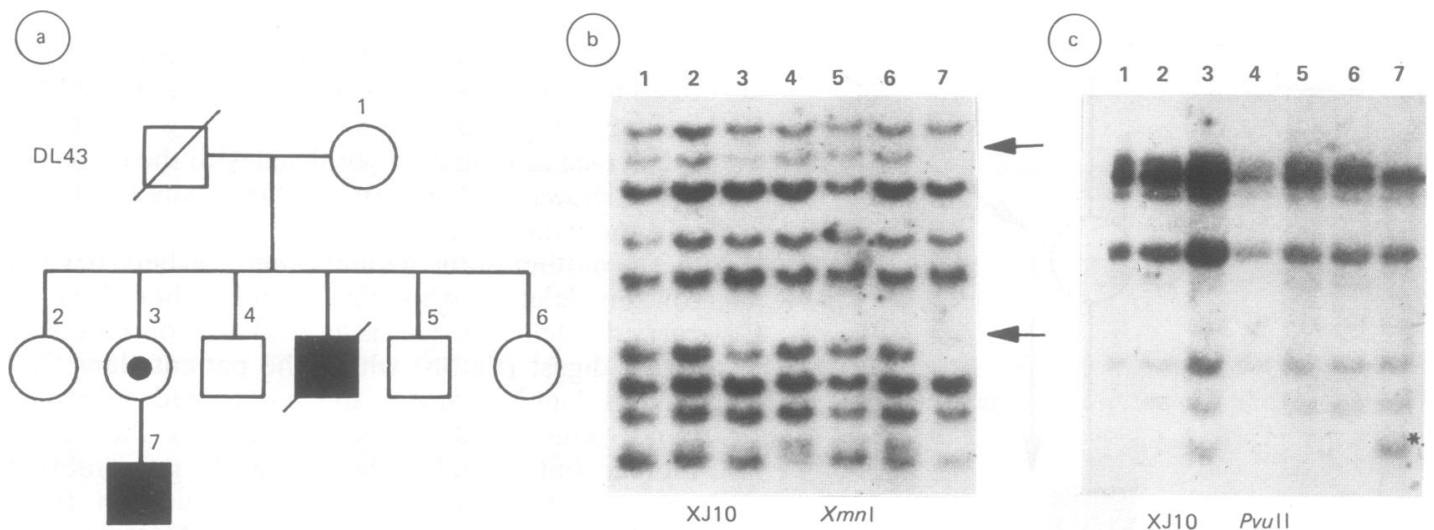

FIG 3 (a) Family DL43; the index patient (7) is carrying a partial gene deletion, his mother (3) is a carrier of the same mutation, and her brother died of DMD. The grandmother (1) did not carry the DMD mutation but as she transmitted the mutation twice, she must have been a germinal mosaic. (b) On an XmnI Southern blot hybridised with cDNA-XJ10 (0-2), the patient's deletion is clearly seen; deleted exon bands are indicated with an arrow. There is also a weak junction band visible, just above the lower missing band. The mother of the patient is a carrier of the mutation on the basis of the intensity of the deleted bands. (c) On a Pvull digest the junction band (indicated with an asterisk) in the patient's DNA is clearly present in his mother's DNA. The grandmother lacks the junction band, so she is not a carrier somatically.

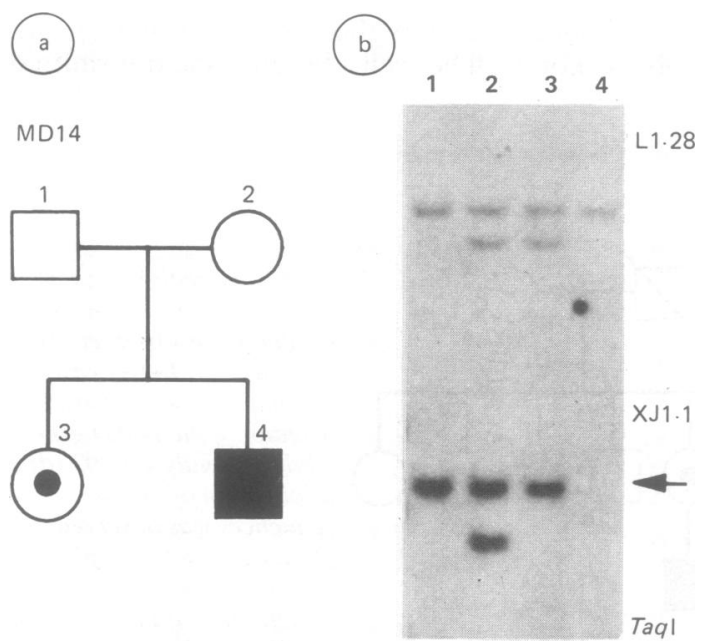

FIG 4 (a) Family MD14. The patient and his sister are both carrying a deletion mutation for XJ1.1. (see also 4b). Their mother is not carrying this mutation in her somatic (white blood cell) DNA, but has transmitted the mutation twice; therefore she is carrying a germinal mosaic for this DMD mutation. (b) A TaqI Southern blot of family MD14, simultaneously hybridised with the intragenic probe $X J 1.1$ and the extragenic control probe L1.28. Both probes detect RFLPs for TaqI and are informative in the mother of the patient (lane 2). Thus, the mother is not carrying the XJ1.1 deletion observed in the patient (arrow). The daughter, however, is missing one of the XJ1.1 alleles. Compare the relative intensities of the XJ1.1 signals between mother (lane 2) and daughter (lane 4) relative to the L1.28 signals. The daughter is missing one XJ1.1 allele, thus carrying the same mutation as her affected brother. the same $\mathrm{X}$ chromosome in an unaffected form to her daughter (lane 3) on the basis of flanking markers OTC and pD2. The alternative explanation for the unaffected $\mathrm{X}$ haplotype in the sister is a double crossover, which should occur in less than $1 \%$ of cases. Because of the intensity difference observed in the junction band of the mother's DNA (fig 5d, lane 1, where the band has a lesser intensity than that of lane 4, a full carrier), a somatic mosaic situation is probably present in this case.

\section{Discussion}

The detection of six cases of apparent multiple transmission of 'new' mutations out of 42 studied indicates that this phenomenon is relatively frequent. The most plausible explanation for such multiple transmission, when the absence of mutation in lymphocytes is taken into account, is germinal mosaicism. Moreover, this frequency of gonadal mosaicism is an underestimate, because in 16 of the 28 families (table 2) the at risk haplotype was transmitted only once and gonadal mosaicism could not be assessed. When families were counted in which the same $X$ haplotype was present in one or more sibs, six recurrent mutations were detected in 28 families among 41 meioses in which the at risk haplotype was transmitted. This implies a $14 \%$ recurrence risk for mothers of patients with an identified new mutation when considering male pregnancies with the same $X$ haplotype and an a priori $7 \%$ risk for a male fetus where the haplotype information is absent. 


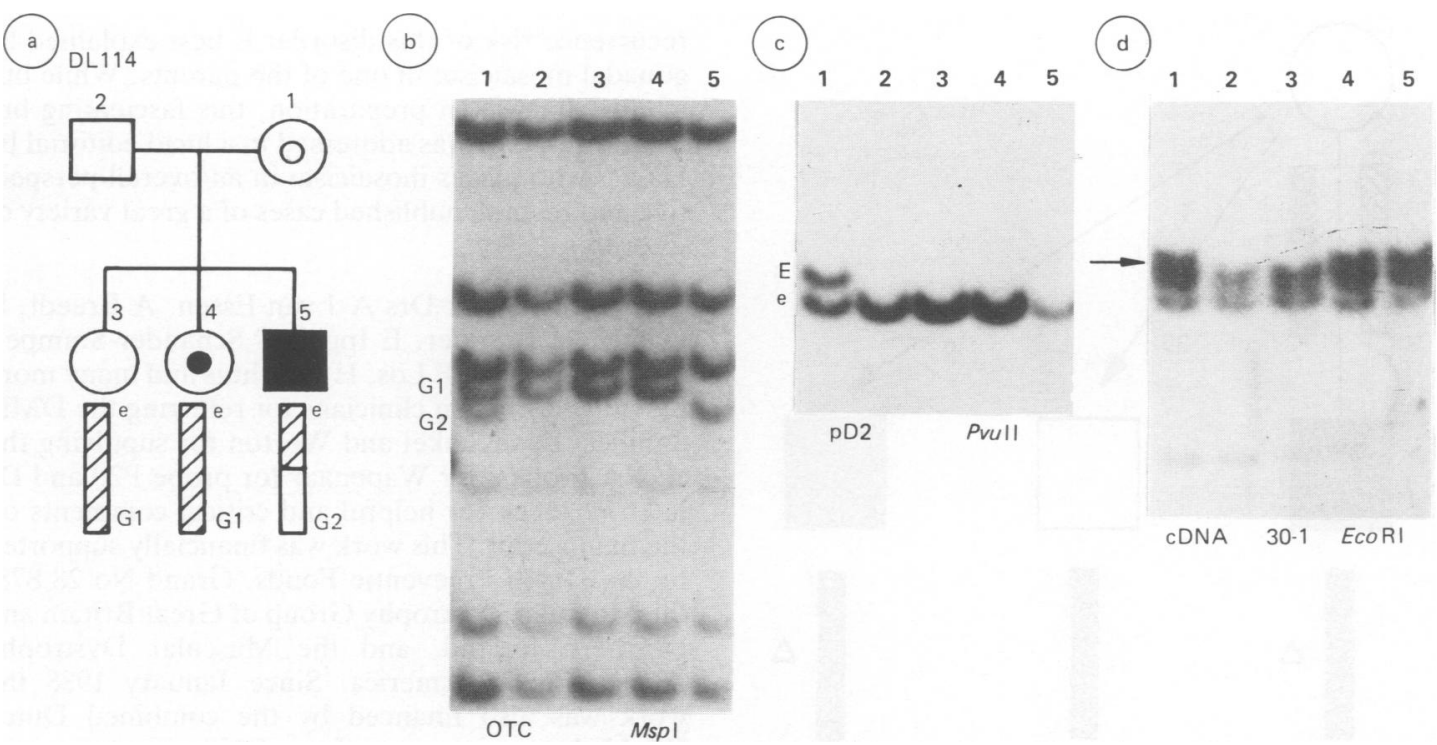

FIG 5 (a) Pedigree of family DL114. The DMD patient's X chromosome identified as $e-G 2$ (for the flanking markers pD2 and OTC; see also fig $5 b$ and $c$ ) is most likely a recombinant haplotype, because both his sisters inherited an $X$ chromosome with the haplotype e-G1 from their mother. The DMD patient has a partial gene deletion detected by $c D N A 3 b-5 a$ (see fig $5 d)$, one of the sisters and the mother carry the deletion, and the other sister (3) does not, although she had the same $X$ chromosome. The mother of the patient is carrying the mutation both as a germinal and as a somatic mosaic (indicated with an operi circle): she passed a normal e-G1 X haplotype to daughter 3 , an affected e-G1 to daughter 4, and an affected recombinant X e-G2 to the patient. (b) Southern blot of family DL114 (MspI) hybridised with the OTC probe located proximal to the DMD gene. The mother (lane 1) is informative for G1/G2, both daughters are homozygous G1/G1, and the affected son has the G2 allele. (c) PvuII Southern blot showing that both daughters and the affected son did inherit the same allele (e) from their mother (lane 1) who is heterozygous for pD2 (E/e), a probe located distal to the DMD gene. (d) Part of an EcoRI Southern blot, hybridised with cDNA3b-5a, detecting the deletion junction band in the patient's DNA (lane 5) indicated with an arrow. The junction band is present in the DNA of one daughter (lane 4), but absent in the DNA of the other daughter (lane 3). The mother (lane 1) is definitely carrying the same mutation, but most likely as a somatic mosaic (not all her cells carry the mutation). The junction band, although difficult to see on the photo of the blot, is slightly weaker in intensity.

In contrast to the theoretical considerations of Hartl ${ }^{14}$ and Murphy et al, ${ }^{15}$ our recurrence risk estimates are based on empirical data and can be directly applied to genetic counselling in DMD. Until more data are available, genetic counsellors are advised to use a recurrence risk of approximately $7 \%(14 \%$ if the at risk $\mathrm{X}$ haplotype is known) when counselling sisters and mothers of an apparently new DMD mutant. If the mutation (deletion or duplication) is detectable in the patient, highly reliable prenatal diagnosis is possible in subsequent pregnancies of apparent non-carrier mothers and should be carried out to prevent the birth of additional patients. If the mutation is not (yet) detectable, the assessment of new mutants relies on haplotype information (for example, healthy brothers having the same haplotype as the affected). In those cases prenatal diagnosis based on $\mathrm{X}$ haplotype information either leads to the exclusion of the at risk $X$ chromosome or a $14 \%$ recurrence risk for male pregnancies. It should be noted that results given earlier to relatives of so called new DMD cases need complete reconsideration.

Our findings do not only bear on diagnostic accuracy, but also have fundamental implications. One of them is that because the recurrent new mutations occur so much more commonly than previously thought, the published recombination data of flanking markers might be biased by mosaicism. For instance, we originally scored two recombinants between $754(D X S 84)$ and $D M D$ in family DL43. Since the deletion itself is now detectable in this family, we know that these recombinants were erroneously scored because of the unexpected segregation caused by gonadal mosaicism. Similar cases may explain many of the contradicting 


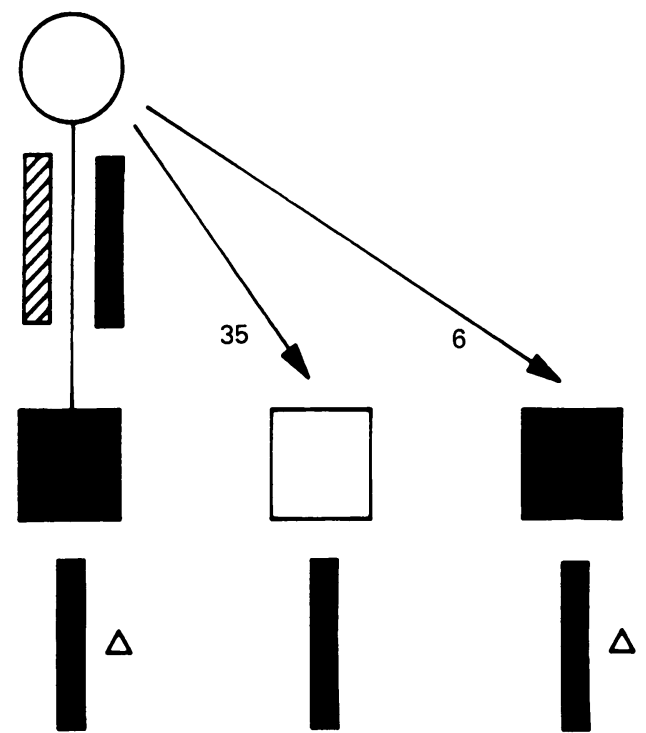

FIG 6 This figure illustrates germinal mosaicism and the risk of recurrence in a following child. In 28 families (see table 2) the new mutant $X$ haplotype was transmitted 41 times, 35 times normal and six times affected. The risk for this haplotype to be affected is $14 \%$, because of germinal mosaicism in the mother.

genetic distances obtained earlier between $D M D$ and close markers. ${ }^{221} 22$ Secondly, while the overall mutation frequency should not be affected by the observation of mosaicism, a much better understanding is gained of the point in development at which mutation takes place. Our findings of an almost equal male and female mutation rate supports a probable mitotic origin for many, if not most, DMD mutations. Somatic mosaicism may also occur, as described for haemophilia $A^{23-25}$ and for DMD (this study, fig 5, DL114). We must emphasise that since we have only investigated blood, the presence of combined somatic gonadal mosaicism cannot be excluded in the other cases. The use of specific sequences and the PCR technique could be of help in the detection of somatic mosaicism. For males, the presence of somatic mosaicism of $X$ linked mutations may well result in a milder form of the same disorder, as recently reported for OTC deficiency. ${ }^{26}$ It is becoming increasingly clear that mosaicism for new mutations is not limited to DMD or even to $\mathrm{X}$ linked recessive disorders and that it will probably play a role in many inherited diseases. Recently, Byers et $\mathrm{ll}^{27}$ reported data on the recurrence risk of autosomal dominant osteogenesis imperfecta. They hypothesised that the $6 \%$ empirical recurrence risk of this disorder is best explained by gonadal mosaicism in one of the parents. While our manuscript was in preparation, this fascinating but complex matter was addressed in a lucid editorial by Hall, ${ }^{28}$ who places mosaicism in an overall perspective and reviews published cases of a great variety of disorders.

We wish to thank Drs A J van Essen, A Breedt, B Hamel, H Brunner, E Ippel, C Schander-Stumpel, C Die-Smulders, F Los, H Oorthuis and many more Dutch and Belgian clinicians for referring the DMD families; Drs Kunkel and Worton for supplying the cDNA probes; Dr Wapenaar for probe P20 and Dr K H Fishbeck for helpful and critical comments on the manuscript. This work was financially supported by the Dutch Praeventie Fonds, Grand No 28.878, the Muscular Dystrophy Group of Great Britain and Northern Ireland, and the Muscular Dystrophy Association of America. Since January 1988 the work was also financed by the combined Dutch Health Insurances to perform DNA diagnosis.

\section{References}

1 Emery AEH. Duchenne muscular dystrophy. In: Motulski AG, Harper PS, Bobrow M, Scriver C, eds. Oxford monographs on medical genetics. No 15. Revised edition. Oxford: Oxford University Press, 1988.

2 Bakker E, Hofker MH, Goor N, et al. Prenatal diagnosis and carrier-detection of Duchenne muscular dystrophy with closely linked RFLPs. Lancet 1985;i:655-8.

${ }^{3}$ Bakker E, Bonten EJ, de Lange LF, et al. DNA probe analysis for carrier detection and prenatal diagnosis of Duchenne muscular dystrophy: a standard diagnostic procedure. J Med Genet 1986;23:573-80.

${ }^{4}$ Bakker E, Bonten EJ, Veenema H, et al. Prenatal diagnosis of Duchenne muscular dystrophy: a three year experience in a rapidly evolving field. J Inherited Metab Dis (in press).

5 Darras BT, Harper JF, Francke U. Prenatal diagnosis and detection of carriers with DNA probes in Duchenne's muscular dystrophy. N Engl J Med 1987;316:985-92.

6 Darras BT, Koenig M, Kunkel LM, Francke U, Direct method for prenatal diagnosis and carrier detection in Duchenne/Becker muscular dystrophy using the entire dystrophin cDNA. Am J Med Genet 1988;29:713-26.

${ }^{7}$ Forrest SM, Cross GC, Thomas NST, et al. Effective strategy for prenatal prediction of Duchenne and Becker muscular dystrophies. Lancet 1987;ii:1294-7.

${ }^{8}$ Den Dunnen JT, Bakker E, Klein Breteler EG, Pearson PL, van Ommen GJB. Direct detection of more than $50 \%$ of the Duchenne muscular dystrophy mutations by field inversion gels. Nature 1987;329:640-2.

9 Forrest SM, Cross GS, Speer A, Gardner-Medwin D, Burn J, Davies KE. Preferential deletions of exons in Duchenne and Becker muscular dystrophy. Nature 1987;329:638-40.

${ }^{10}$ Monaco ÁP, Neve RL, Colletti-Feener CA, Bertelson CA, Kurnit DM, Kunkel LM. Isolation of candidate cDNAs for portions of the Duchenne muscular dystrophin gene. Nature 1986;323:646-50.

" Koenig M, Hoffman EP, Bertelson CJ, Monaco AP, Feener C, Kunkel LM. Complete cloning of the Duchenne muscular dystrophy (DMD) cDNA and preliminary genomic organization of the DMD gene in normal and affected individuals. Cell 1987;50:509-17. 
12 Den Dunnen JT, Bakker E, Grootscholten PM, van Broeckhoven C, Pearson PL, van Ommen GJB. Topography of the DMD gene. Am J Hum Genet (submitted).

13 Haldane JBS. The rate of spontaneous mutation of a human gene. J Genet 1935;31:317-26.

14 Hartl DL. Recurrence risks for germinal mosaics. Am J Hum Genet 1971;23:124-34.

15 Murphy EA, Cramer DW, Kryscio RJ, Brown CC, Pierce ER. Gonadal mosaicism and genetic counseling for $\mathrm{X}$-linked recessive lethals. Am J Hum Genet 1974;26:207-22.

16 Monaco AP, Bertelson CJ, Colletti-Feener C, Kunkel LM. Localization and cloning of Xp deletion breakpoints involved in muscular dystrophy. Hum Genet 1987;75:221-7.

17 Bakker E, Van Broeckhoven C, Bonten EJ, et al. Germline mosaicism and Duchenne muscular dystrophy mutations. Nature 1987;329:554-6.

18 Darras BT, Francke U. A partial deletion of the muscular dystrophy gene transmitted twice by an unaffected male. Nature 1987;329:556-8.

19 Wood S, McGillivray B. Germinal mosaicism in Duchenne muscular dystrophy. Hum Genet 1988;78:282-4.

${ }^{20}$ Pearson PL, Kidd KK, Willard HF. Human gene mapping in recombinant DNA techniques. Committee report, HGM9, Paris. Cytogenetic Cell Genet 1987;43:390-566.

${ }^{21}$ Fishbeck KH, Ritter AW, Tirschwell DL, et al. Recombination with pERT87 in families with X-linked muscular dystrophy. Lancet 1986;ii:104.
2 Harper PS, Williams SH, Thomas N, Sarfarazi M. Prenatal diagnosis of Duchenne dystrophy. Lancet 1985;i:872.

23 Gitschier J. Maternal duplication associated with gene deletion in sporadic hemophilia. Am J Hum Genet 1988;43:274-9.

24 Bröcker-Vriends AHJT, Briët E, Dreeson JCFM, et al. Somatic and germinal mosaicism for a deletion in the clotting factor VIII gene. (Submitted).

2s Higuchi M, Kochhan L, Olek K. A somatic mosaic for haemophilia A detected at the DNA level. Mol Biol Med 1988;5:23-7.

${ }^{26}$ Maddalana A, Sosnoski DM, Berry GT, Nussbaum RL. Mosaicism for an intragenic $\mathrm{X}$ chromosome deletion in a male with mild ornithine transcarbamylase deficiency. Am J Hum Genet 1988;47:227A.

${ }^{27}$ Byers PH, Tsipouras P, Bonadio JF, Starman J, Schwartz RC. Perinatal lethal osteogenesis imperfecta (OI type II): a biochemically heterogeneous disorder usually due to new mutations in the genes for type I collagen. Am J Hum Genet 1988;42: $237-48$.

${ }^{28}$ Hall J. Review and hypotheses. Somatic mosaicism. observations related to clinical genetics. Am J Hum Genet 1988;43: $355-63$.

Correspondence to Dr E Bakker, Department of Human Genetics, Sylvius Laboratories, Wassenaarseweg 72, 2333AL Leiden, The Netherlands. 